\title{
Mielopatia por embolismo fibrocartilaginoso em um canino
}

\author{
Fibrocartilaginosus embolic myelopathy in a dog \\ Elisa Scheid Tesser', Saulo Petinatti Pavarini', Pedro Soares Bezerra Júnior'1, \\ Juliana de Aguiar Marcato', Nadia Aline Bobbi Antoniassi', \\ Rodolfo Voll ${ }^{2}$ \& David Driemeier'
}

\begin{abstract}
RESUMO
Mielopatia por embolismo fibrocartilaginoso é uma síndrome caracterizada por um infarto da medula espinhal causado por êmbolos fibrocartilaginosos idênticos ao núcleo pulposo do disco intervertebral. Esta doença é descrita em diversas espécies animais incluindo humanos. O presente relato ocorreu em um canino de seis anos, macho Dogue Alemão que mostrou paralisia súbita dos membros pélvicos e foi eutanasiado doze dias após o início da paralisia. Na necropsia havia severa distensão da bexiga e áreas necróticas na medula espinhal foram observadas no exame macroscópico. Microscopicamente, extensas áreas de malácia circundadas por células gitter, hemorragia e edema, alcançando as substâncias cinzenta e branca. Êmbolos fibrocartilaginosos estavam presentes no interior da medula espinhal e vasos da leptomeninge. Dados relacionados à patologia e sinais clínicos serão apresentados e discutidos.
\end{abstract}

Descritores: mielopatia, embolismo, fibrocartilaginoso.

\begin{abstract}
Fibrocartilaginous embolic myelopathy is a syndrome of spinal cord infarction caused by fibrocartilaginous emboli identical to the nucleus pulposus of the intervertebral disk. This disease is described in several animals species including humans. In this case a six-year-old male Great Dane showed sudden pelvic members paralysis. Twelve days after the onset of paralytic signs the dog was euthanatized. Severe distention of the urinary bladder and necrotic areas in the spinal cord were observed in the macroscopic examination. Histological examination revealed extensive areas of malacia surrounded by gitter cells, hemorrhage and edema, evolving grey and white matter. Fibrocartilaginous emboli were present into the spinal cord and leptomeningeal vessels. Data related and pathologic and clinical signs findings will be presented and discussed.
\end{abstract}

Keywords: myelopathy, embolic, fibrocartilaginosus. 


\section{INTRODUÇÃO}

A mielopatia por embolismo fibrocartilaginoso é uma síndrome caracterizada por um infarto agudo da medula espinhal causada por êmbolos de fibrocartilagem, histologicamente idênticos ao núcleo pulposo dos discos intervertebrais [2]. Esta doença é de ocorrência esporádica e tem sido descrita em cães [4], gatos [10], suínos [1], equinos [13], bovinos [9], perus [14], animais selvagens [8,12] e humanos [7]. Em cães, esta enfermidade acomete principalmente animais adultos de grande porte (raças grandes e gigantes). Sinais clínicos surgem repentinamente e são consequências da malácia devido à oclusão de vasos das meninges e da medula espinhal por êmbolos de fibrocartilagem. Assim a manifestação varia de acordo com a distribuição e severidade referentes ao sítio e extensão das lesões isquêmicas [9]. O diagnóstico definitivo depende da demonstração histológica dos êmbolos fibrocartilaginosos intravascular e necrose associada a segmentos da medula espinhal [4]. O objetivo do trabalho é relatar um caso de mielopatia por embolismo fibrocartilaginoso em canino adulto da raça Dogue Alemão, dando ênfase aos achados clínicos e patológicos desta enfermidade.

\section{MATERIAIS E MÉTODOS}

No mês de outubro de 2007, foi atendido no Hospital de Clínicas Veterinárias da Universidade Federal do Rio Grande do Sul (HCV-UFRGS), um canino macho da raça Dogue Alemão de 6 anos de idade. Este foi submetido a exame clínico e neurológico. Após 12 dias de curso da doença e pelo prognóstico desfavorável o proprietário optou pela eutanásia do cão. $\mathrm{O}$ animal foi encaminhado ao Setor de Patologia Veterinária (SPV) da Universidade Federal do Rio Grande do Sul (UFRGS) para a realização de necropsia. Fragmentos de diversos órgãos foram coletados e fixados em solução de formalina $10 \%$. Os mesmos foram processados pelos métodos de rotina e corados pela técnica Hematoxilina e Eosina (HE) [11]. Fragmentos de medula foram submetidos a coloração de Alcian Blue pH 2,5 [11].

\section{RELATO DE CASO}

Doze dias antes do óbito do animal, o proprietário o conduziu ao canil, no período da manhã, como de costume, sem que fosse observada nenhuma alteração. Logo após, ainda no período da manhã, observaram que o paciente não conseguia andar com os membros pélvicos (MsPs). No dia seguinte, foi encaminhado ao HCV-UFRGS para atendimento clínico. O exame neurológico evidenciou paralisia de neurônio motor inferior (NMI) dos MsPs, bexiga, ânus e cauda. O pinçamento digital dos MsPs evidenciou ausência de dor profunda. O reflexo panicular (reflexo cutâneo do tronco) encontrava-se ausente caudalmente ao terço torácico médio. Havia ausência de manifestação de dor à palpação da coluna toracolombar. Os membros torácicos apresentavam reações posturais e reflexos normais. Não havia sinais de alteração encefálica. $\mathrm{O}$ animal manteve-se durante 12 dias sem movimentação dos membros pélvicos e apresentava incontinência urinária e fecal. Houve surgimento de escaras de decúbito e assaduras nos MsPs e escroto em função da paralisia dos membros. Devido à gravidade do quadro e prognóstico desfavorável, o proprietário optou pela eutanásia.

Durante a necropsia, no exame macroscópico, foi observado aumento de volume acentuado na região do escroto com múltiplas áreas de ulceração, escaras nos membros pélvicos e, em menor quantidade, nos membros torácicos. Os testículos apresentavam edema peritesticular intenso e a bexiga estava distendida (Figura 1). Na medula espinhal, caudal a intumescência lombo-sacral, havia áreas enegrecidas, amareladas (necrose) principalmente na região ventral se estendendo à região dorsal (Figura 2). Não foram observadas extrusões ou protrusões de discos intervertebrais. No exame histopatológico, a principal alteração foi visualizada na medula espinhal, caracterizada por extensas áreas de malácia, com grande número de células de gitter, hemorragia e edema (Figura 3), atingindo a substância cinzenta e branca. Adjacente às áreas de necrose e nas raízes dorsais e ventrais, há moderada quantidade de axônios tumefeitos (degeneração walleriana) ou ausentes, com vacuolização da substância branca. Êmbolos fibrocartilaginosos (Figura 4), caracterizados por um material eosinofílico hialino, corados pela coloração de Alcian Blue foram observados no interior de vasos da leptomeninge e medula. Nestes vasos, foi observada uma moderada proliferação de fibroblastos perivascular. Estes êmbolos obstruíam total ou parcialmente a luz dos vasos e, por vezes, recobertos por células endoteliais sugerindo recanalização.

\section{DISCUSSÃO}

O diagnóstico de mielopatia por embolismo fibrocartilaginoso no presente caso foi baseado nos sinais clínicos apresentados pelo cão, associado aos achados de necropsia e histopatológicos. A presença de extensas 
Tesser E.S., Pavarini S.P., Bezerra Jr. P.S., Marcato J.A., Antoniassi N.A.B., Voll R. \& Driemeier D. 2009. Mielopatia por embolismo

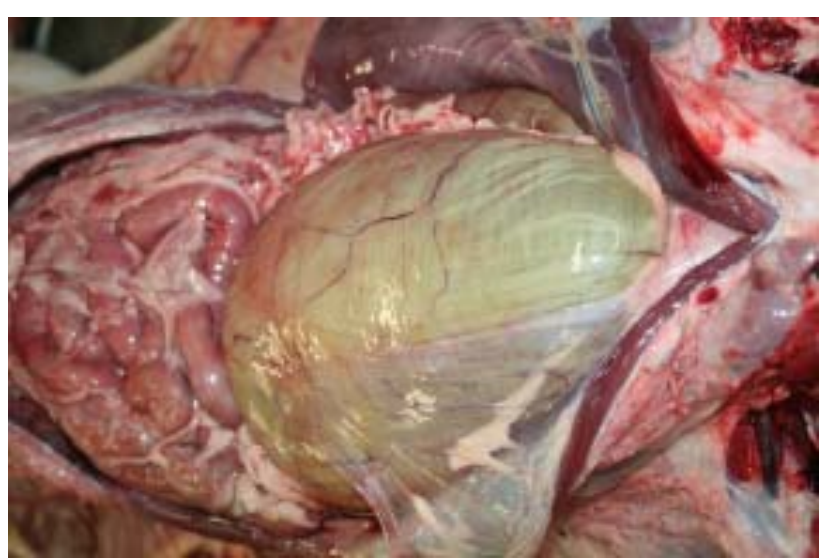

Figura 1. Bexiga distendida ocupando grande parte da cavidade abdominal.

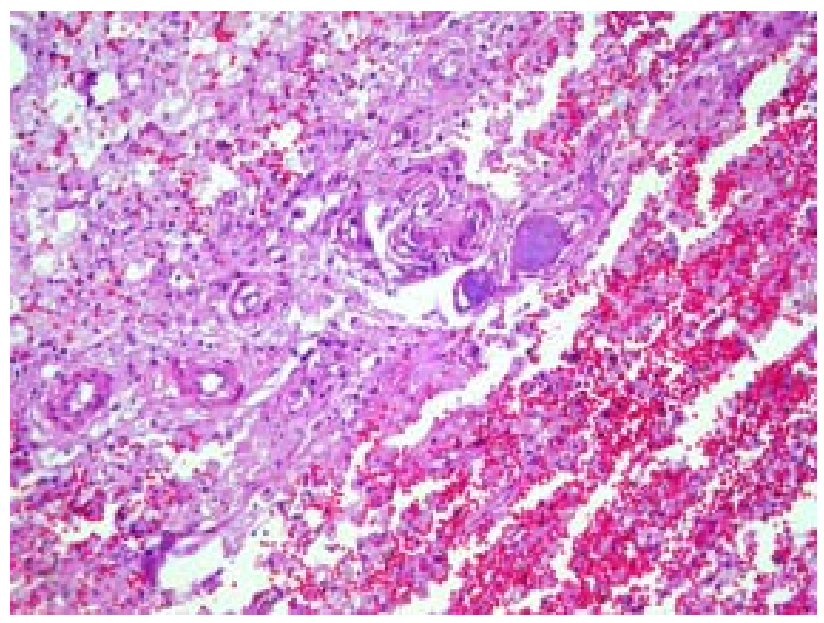

Figura 3. Medula espinhal: extensa área de malácia, com grande número de células de gitter e hemorragia. Vasos centrais ocluídos por êmbolos de fibrocartilagem corados em azul (Alcian Blue contra corado com HE, obj. 40).

áreas de necrose com a oclusão de veias e artérias da medula espinhal e meninges por êmbolos fibrocartilaginosos com aspecto histológico idêntico a do núcleo pulposo são achados considerados característicos dessa doença [1-3,9]. Traumatismos e exercícios vigorosos são tidos como fatores predisponentes para o desenvolvimento da mielopatia fibrocartilaginosa, porém, neste caso, não foi observada nenhuma alteração durante a necropsia sugestiva de traumatismo e o cão não tinha histórico de realização de exercícios vigorosos na véspera do ocorrido $[1,3,6]$. O mecanismo de entrada dos êmbolos na circulação não é bem conhecido $[4,5,9,15]$. Uma das teorias mais aceitas é que, devido a um aumento da pressão intradiscal, há a liberação de êmbolos de fibrocartilagem provenientes do núcleo pulposo

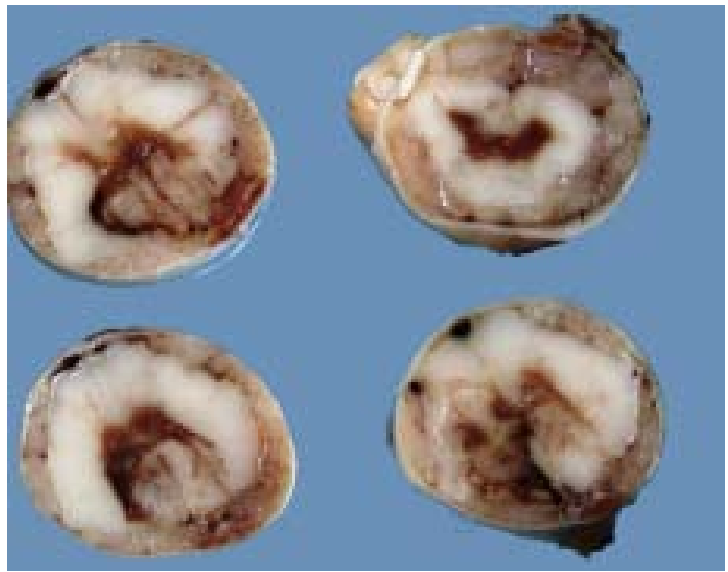

Figura 2. Medula espinhal, caudal a intumescência lombosacral, áreas enegrecidas, amareladas (necrose) principalmente na região ventral se estendendo à região dorsal.

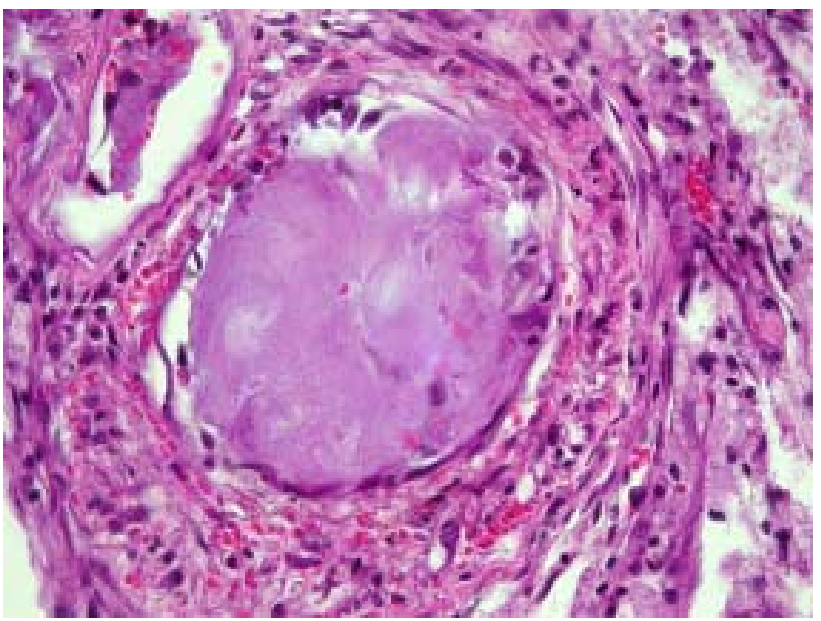

Figura 4. Vaso da leptomeninge da medula espinhal, preenchido por um material eosinofílico hialino, compatível com êmbolo de fibrocartilagem (HE, obj. 100).

vertebral para dentro das artérias vertebrais por fluxo retrógrado. Estes alcançam a medula espinhal seguindo o fluxo sanguíneo normal [1-3,7]. A bexiga distendida, ausência de movimento nos membros pélvicos e de tônus do esfíncter anal devem-se à paralisia de neurônio motor inferior ocasionado pela necrose da medula espinhal [1-5]. A progressão dos sinais clínicos pode ser relacionada com a expansão da isquemia e suas sequelas tais como malácia e hemorragia em áreas adjacentes da medula espinhal [4]. Os principais diagnósticos diferenciais a serem levados em consideração incluem traumatismos e protrusões de disco intervertebral aguda, porém, nesses dois casos, além da observação de lesões distintas na necropsia, o animal manifesta clinicamente um quadro de algia [6]. 


\section{REFERÊNCIAS}

1 Benson J.E. \& Schwartz K.J. 1998. Ischemic myelomalacia associated with fibrocartilaginous embolism in multiple finishing swine. Journal of Veterinary Diagnostic Investigation. 10: 274-277.

2 Cauzinille L. \& Kornegay J.N. 1996. Fibrocartilaginous embolism of the spinal cord in dogs: review of 36 histologically confirmed cases and retrospective study of 26 suspected cases. Journal of Veterinary Internal Medicine. 10: 241-245.

3 Fuentealba C., Weeks B.R., Martin M.T., Joyce J.R. \& Wease G.S. 1991. Spinal cord ischemic necrosis due to fibrocartilaginous embolism in a horse. Journal of Veterinary Diagnostic Investigation. 3: 176-179.

4 Gandini G. \& Cizinauskas S. 2003. Fibrocartilaginous embolism in 75 dogs: clinical findings and factors influencing the recovery rate. Journal of Small Animal Practice. 44: 76-80.

5 Gill C.W. 1979. Fibrocartilaginous embolic myelopathy in a Dog. The Canadian Veterinary Journal. 20: 273-278.

6 Greene C.E. \& Higgins R.J. 1976. Fibrocartilaginous emboli as the cause of ischemic myelopathy in a dog. The Cornell veterinarian. 66: 131-142.

7 Han J.J., Massagli T.L. \& Jaffe K.M. 2004. Fibrocartilaginous embolism - an uncommon cause of spinal cord infarction: a case report and review of the literature. American Journal of Physical Medicine \& Rehabilitation. 85: 153-157.

8 Johnson R.C., Anderson W.I. \& King J.M. 1988. Acute pelvic limb paralysis induced by a lumbar fibrocartilaginous embolism in a sow. The Cornell veterinarian. 78: 231-234.

9 Landolfi J.A., Saunders G.K. \& Swecker W.S. 2004. Fibrocartilaginous embolic myelopathy in a calf. Journal of Veterinary Internal Medicine. 16: 360-362.

10 Mikszewski J.S., Van Winkle T.J. \& Toxel M.T. 2006. Fibrocartilaginous embolic myelopathy in five cats. Journal of the American Animal Hospital Association. 42: 226-233.

11 Prophet E.B., Mills B., Arrington J.B. \& Sobin L.H. 1992. Laboratory Methods in Histotechnology. Washington: American Registry of Pathology, 279p.

12 Renner M.S., Bryant W. \& Kennedy G.A. 1998. Fibrocartilaginous emboli in a tayra (Eira Barbara): a case reported. Journal of Zoo and Wildlife Medicine. 29: 470-473.

13 Sebastian M.M. \& Giles R.C. 2004. Fibrocartilaginous embolic myelopathy in a horse. Journal of Veterinary Internal Medicine. 51: 341-343.

14 Stedman N.L., Brown T.P. \& Rowland G.N. 1998. Intravascular cartilaginous emboli in the spinal cord of turkeys. Avian diseases. 42: 423-428.

15 Tessaro S.V., Doige C.E. \& Rhodes C.S. 1983. Posterior paralysis due to fibrocartilaginous embolism in two weaner pigs. Canadian Journal of Comparative Medicine. 47: 124-126. 